\title{
QUALITY CHARACTERISTICS OF QUERCUS MACEDONICA, Castanea sativa Mill. VS Quercus Alba IN ORDER TO PRODUCE AN INNOVATIVE BALSAMIC VINEGAR PRODUCT
}

\author{
Konstantinos V. Kakavas ${ }^{1 凶}$ \\ ${ }^{1}$ University of Thessaly, Geopolis, 41500 Larisa, Greece, Department of Environment, Laboratory of analytical \\ \& environmental chemistry \\ 凶kakavas@uth.gr \\ https://doi.org/10.34302/crpjfst/2020.12.4.10 \\ Article history: \\ Received: \\ 5 May 2020 \\ Accepted: \\ 1 October 2020 \\ Keywords: \\ Castanea sativa Mill. (CsM); \\ Environmental indicators; \\ Green product; \\ Quercus Alba (QA); \\ Quercus Macedonica (QM); \\ Vinegar.

\section{ABSTRACT} \\ Acetic fermentation is a vital function for microorganisms. Since antiquity, \\ vinegar has been used both to dressing food, but also to characterize the \\ irritable people. The aim of this study was to investigate the quality \\ characteristics of Greek oak (QuercusMacedonica - QM) and Greek \\ chestnut wood (Castanea sativa Mill. - CsM) in comparison with an \\ American oak (Quercus Alba - QA) in order to produce vinegar from grape \\ and apple. This study was conducted to make known the properties both of \\ the Geek Macedonian Quercus and chestnut wood. All official OIV methods \\ were used to implement this study. Volatile acidity increased in the apple \\ vinegar more in QM and less in QA and CsM. In wine vinegar an increase \\ in volatile acidity was observed at about the same level of 28 grams per liter \\ expressed in acetic acid. It has therefore been observed that QM does not \\ behave in the same way and rhythm as other forest species. We observe that \\ QM does not release its ingredients quickly, so it is recommended for long \\ aging of both wines and vinegars. QA and CsM release components from \\ the first month. Polyphenols show a graduation from QM (about $1000 \mathrm{mg} / \mathrm{lt}$ ) \\ to CsM (approximately $15.500 \mathrm{mg} / \mathrm{lt}$ ). All experimental data were confirmed \\ by liquid chromatography. It was found that $\mathrm{QM}$ is best suited for aging \\ apple vinegar. This study helps us to keep vinegar in every type of barrel, so \\ to produce innovative balsamic vinegar.
}

\section{Introduction}

Acidic fermentation is responsible for sulfuric bacteria. These, through the enzymes contained in their cell, transfer oxygen to the alcohol to be oxidized until it is transformed into acetic acid. The history of vinegar is very great. The inhabitants of Attica in Greece called vinegar "idos" which mean pleasure or pleasant to taste. In ancient Lacedaemon (Greece), from the time of the king and legislator of Lykourgos in the 8th century BC century, people and army through the common soups eaten the famous «black broth» and gave them the reputation of prolific warriors. The Roman Empire set out an excellent cuisine in which the vinegar had a prominent place. Each house at the time of the Roman Empire had its own wine cellar (acetumlocum). The Romans used the vinegar to make "posca", the drink of the legionnaires. After they first mixed the vinegar with water, they drank it in order to maintain their strength in the constant campaigns sent by the Roman Empire. Vinegar participates in many metabolic pathways of our organism. Finally, it has a place in local customs, especially in the Holy Week, perhaps because it is connected with the remembrance of the crucifixion and the offering of vinegar by the Roman soldier to the crucified Christ. Acetic acid is the main component of vinegar that plays an important role in the 
release of energy from fats and carbohydrates. It also participates in the building of fats and amino acids. In the body it is transported with blood to the liver and tissues and undergoes complete oxidation with energy release (KawaRygielska et al, 2018). In recent years there has been much talk about the balsamic vinegar of the Italian city of Modena, which is increasingly used in our kitchens. But long time is not the only thing that makes it so delicious and aromatic. It is aging in barrels made of wood of different species and in which vinegar is stored in succession. The maturation within them enriches it with a particular flavor. Polyphenols play an important role in giving flavour and special character to both wines and vinegars (Cerezo et al 2010, Del Alamo Sanza et al 2004, Sanzet al 2012a, Sanzet al2012b, Zhang et al 2015, Figueiredo-González et al 2014, Martínez-Gil et al 2019, Miriam Sanz et al 2011, Psarra et al 2015, Schwarz et al 2009, Tesfaye et al 2004, Bautista-Ortín et al 2008, Cerezo et al 2008, Cerezo et al 2010, Sarni et al 1990, Kanakaki et al 2015, De Rossoet al 2009, Sanz et al 2010, Alañón et al 2011, Karvela et al 2008). While acetic acid, in its pure form, is not so aromatic, it has a distinctly strong odor and irritates the olfactory centers when it comes into contact with them. Rapid induction of ageing character in brandy products is described many scientific projects (Van aarsveld et al 2009). Vinegars derived from sherry winesusually referred in bibliography (García Parrilla et al 1999, Alonso et al 2004). An innovative product of beer vinegar has been recently produced (Mudura et al 2018). In recent works, the chemical characteristics of the Greek CsM have been identified (Kakavas et al 2018, Chavenetidou et al 2019). In the present work we tried to produce an innovative vinegar product by dipping three different types of wood into wine and apple vinegar. It's the first attempt to use Quercus Macedonica for artificial aging of vinegars.

\section{Materials and methods}

\subsection{Materials}

\subsubsection{Samples}

QM was given to us by the forestry authority of the Prefecture of Kozani and comes from Pindosmountain in Greece. The other types of wood and vinegars were purchased from the Greek market.We used glass bottles with a capacity of $300 \mathrm{ml}$, in which $250 \mathrm{ml}$ of apple or wine (white) vinegar and $35 \mathrm{gr}$ of cubed wood were placed. Monthly analyzes were conducted for seven months.Total acidity (gr/lt tartaric acid), volatile acidity by Jaulmes (gr/lt acetic acid) and dry mass were (\%) determined based on Hitos P. et al.Polyphenols were determined by the Folin-Ciocalteumethod: initially, the standard curve $\left(\mathrm{Y}=0,0014 \mathrm{X}+0,0015 \mathrm{R}^{2}=0,993\right)$ was determined with various concentrations of gallic acid. Absorption was set at 765nm.Chromatograms data was performed with HPLC Agilent 1200.All official OIV methods were used to implement this study.

\section{Results and discussions}

\subsection{Chemical Properties of Vinegar Samples}

\subsubsection{Total acidity}

Total acidity has a declining trend for QM, with an increasing trend in QA and CsM before and after wood dipping in apple and wine vinegar (Figure 1). Total acidity was expressed in tartaric acid.

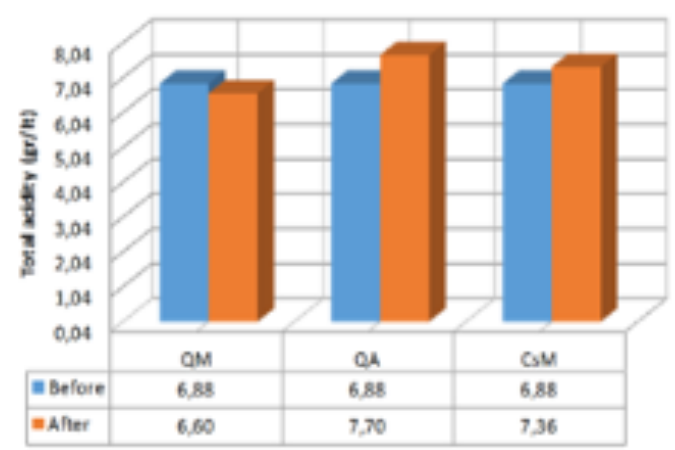




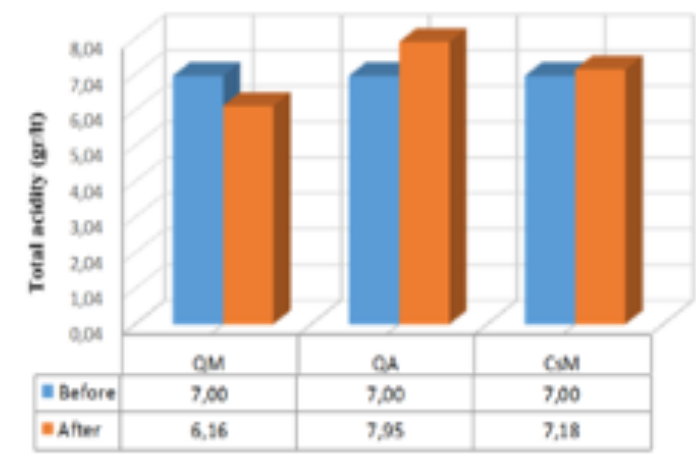

Figure 1. Total acidity of apple vinegar (left) and white vinegar (right).

\subsubsection{Volatile acidity}

Volatile acidity increased in the apple vinegar more in QM (28.7 gr/lt) and less in QA and CsM. In wine vinegar an increase in volatile acidity was observed more in $\operatorname{CsM}(29.1 \mathrm{gr} / \mathrm{lt})$, (Figure 2). Volatile acidity expressed in acetic acid.
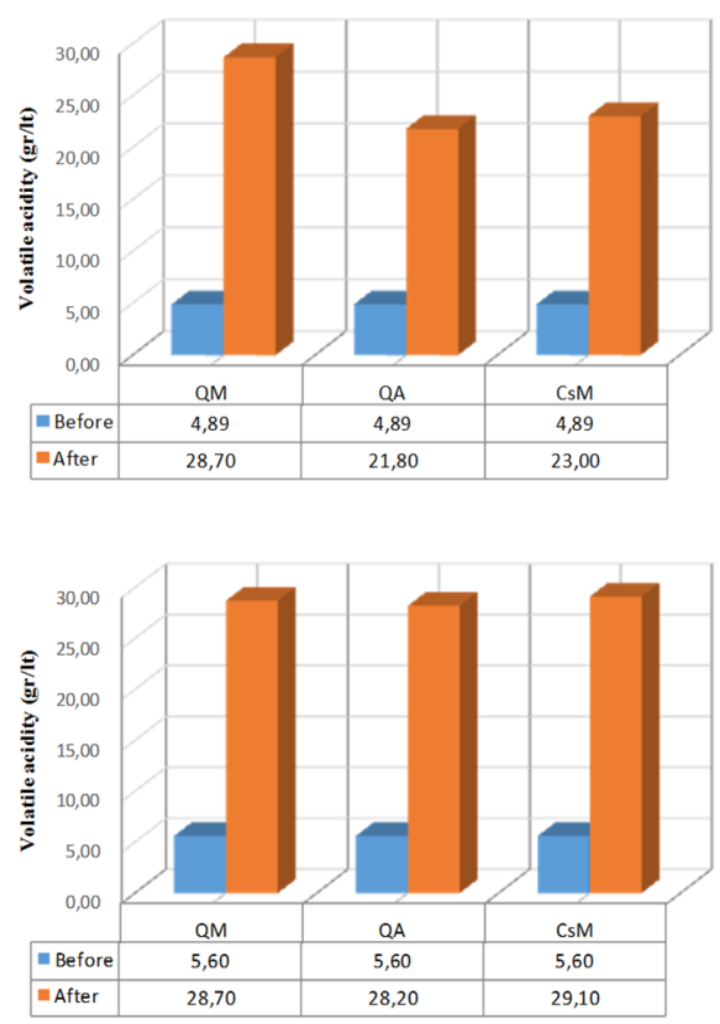

Figure 2.Volatile acidity of apple vinegar (left) and white vinegar (right).

\subsubsection{Total dry mass}

Total dry mass in both apple and wine vinegar is doubled in QA and CsM in relation to QM. It has therefore been observed that QM does not behave in thesame way and rhythm as other forest species (Figure 3).
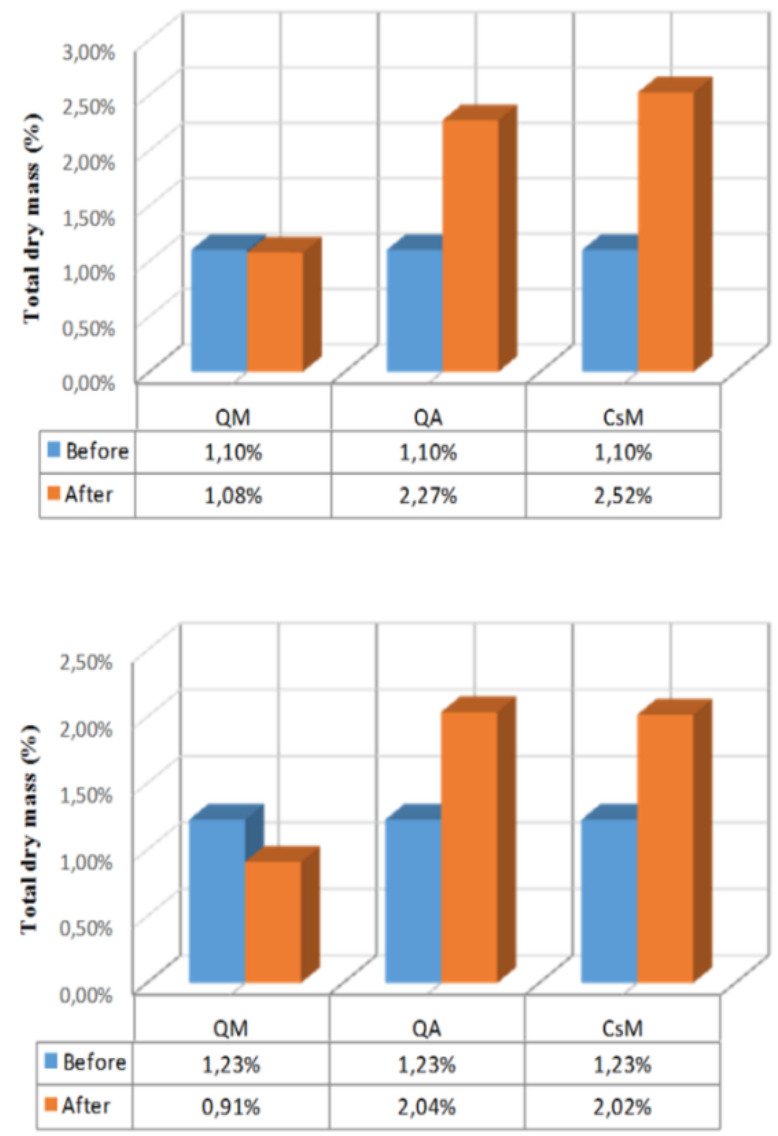

Figure 3. Total dry mass of apple vinegar (left) and white vinegar (right).

\subsection{Biochemical Properties of Vinegar samples}

\subsubsection{Total polyphenols}

It is observed that CsM yields about 15,730 $\mathrm{mg} / \mathrm{lt}$, QA 9,990 mg / lt and QM $1020 \mathrm{mg} / \mathrm{lt}$ total polyphenols for seven months period, representing the average in the case of apple vinegar and grape vinegar (Figures 4, 5). We observe that among the three forest species, CsM yields most polyphenols in both apple vinegar and grape vinegar. In contrast, QM 
yields fewer polyphenols. Polyphenols was expressed in gallic acid.

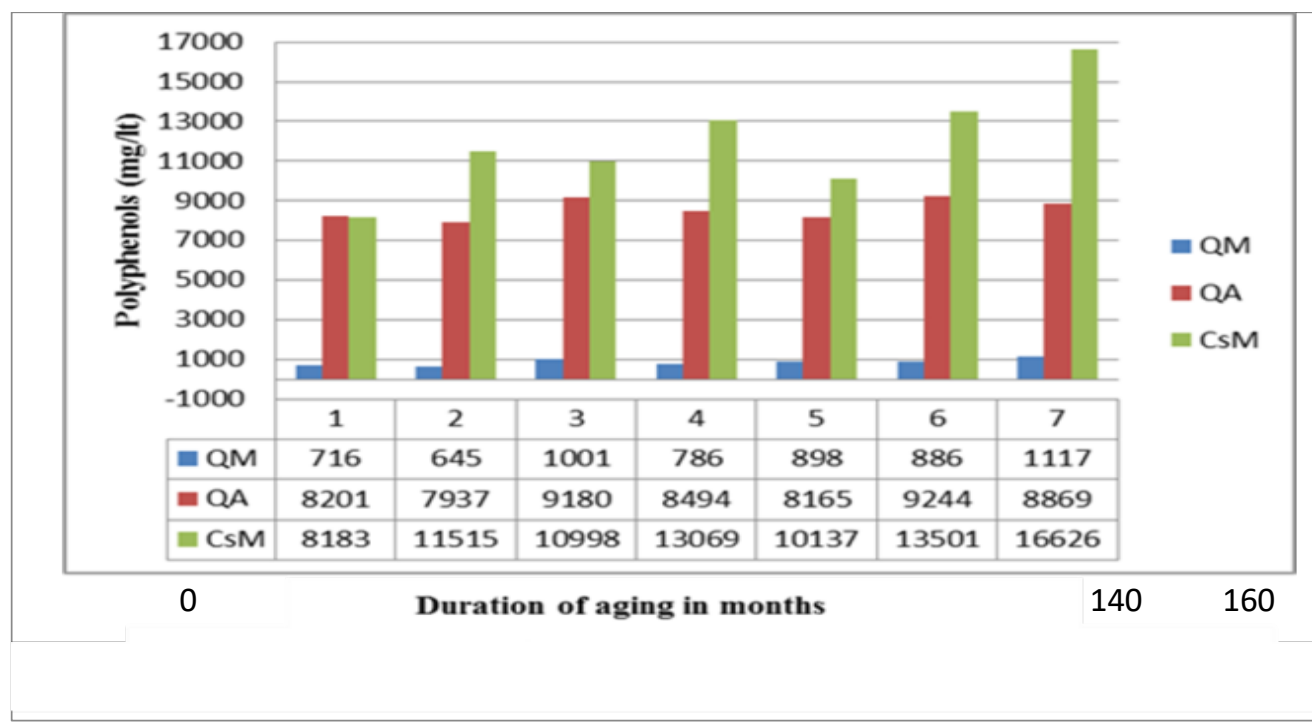

Figure 4.Variation of polyphenols during aging in apple vinegar

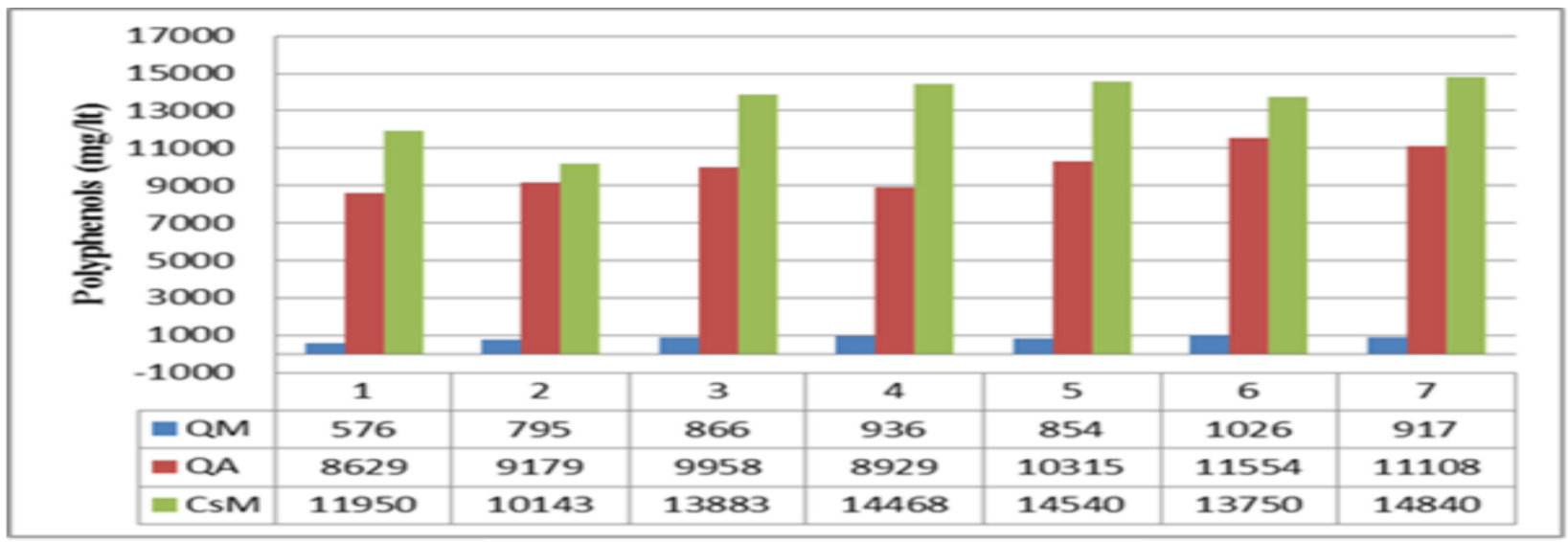

Duration of aging in months

Figure 5. Variation of polyphenols during aging in grape vinegar

\subsubsection{HPLC chromatograms}

If we compare the results of blank (wine vinegar) chromatogram with QM, QA and CsM samples (Figure 6 a - d) we see that, 6a chromatogram shows a limited number of peaks. $6 \mathrm{~b}$ chromatogram shows all the peaks of the blind ( $6 a$ ) but in addition we can see peaks with deferent retention times. From 15 to 20, 22 to 29 and 53 to 56 minutes we can see many peaks. $6 \mathrm{c}$ and $6 \mathrm{~d}$ chromatograms have a variety of peaks and verify that both QA and CsM have a large amount of polyphenols (see also Figure 4 and 5). 

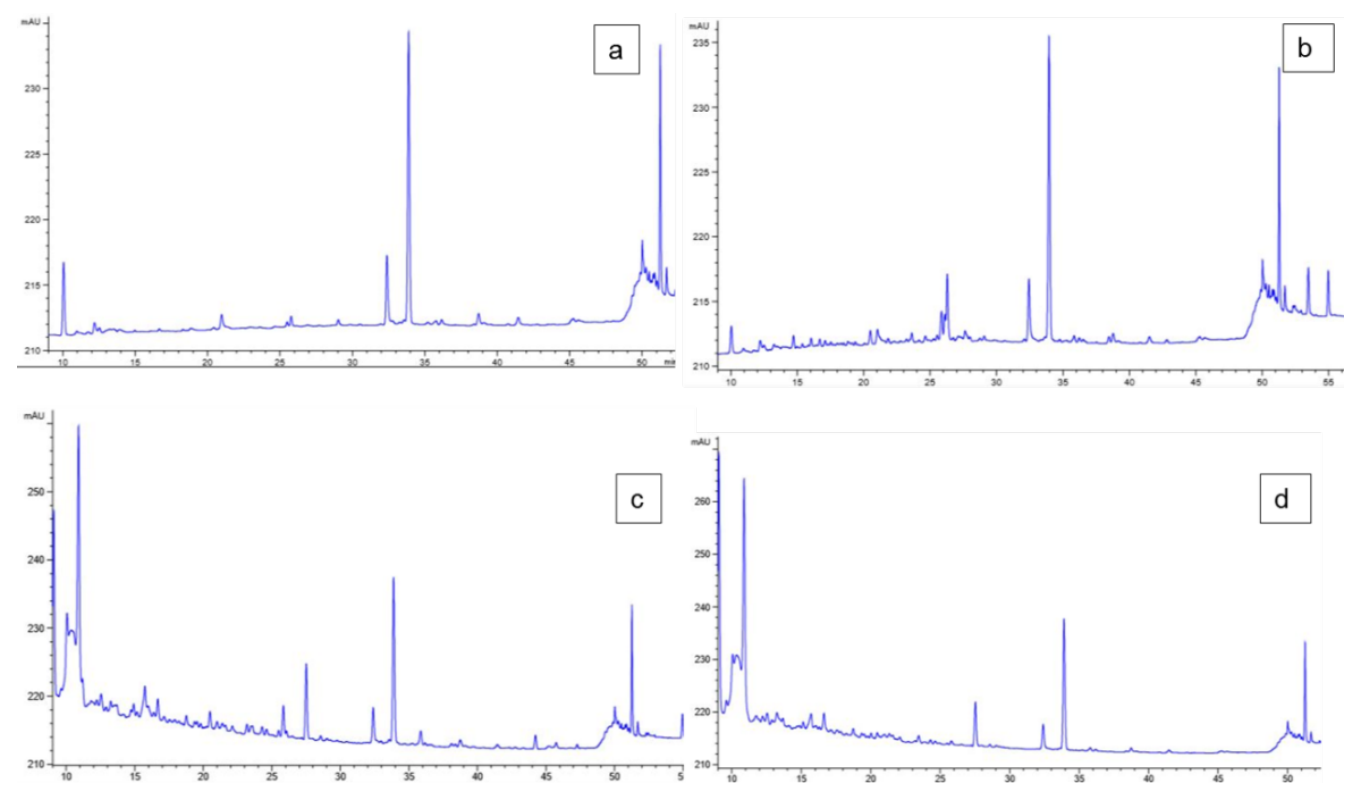

Figure 6.a) blank chromatogram (vinegar from wine), b) QM chromatogram, c) QA chromatogram, d) CsM chromatogram.

\section{Conclusions}

QM can create excellent balsamic vinegar from apples because the increase in volatile acidity has reached high levels(28.7 gr/lt). In contrast CsMcan create excellent balsamic vinegar from wine because the increase in volatile acidity has reached also very high levels(29.1 gr/lt). Total dry mass reached $2.52 \%$ in CsM and over doubled from its initial number $(1.1 \%)$, in the case of apple vinegar. Total dry mass reached $2.04 \%$ toQA $(2.02 \%$ to $\mathrm{CsM})$ in the case of wine vinegar. CsMattributed more polyphenols to both apple vinegar (16.626 $\mathrm{mg} / \mathrm{lt})$ and wine vinegar $(14.840 \mathrm{mg} / \mathrm{lt})$. For this reason, CsM and QM can be used additionally in aging of wines and balsamic vinegars. This study helps us to keep vinegar the proper time period in every type of barrel, so to produce innovative balsamic vinegar.Our work revealed that Greek chestnut (CsM) showed much better quality characteristics than QA, in contrast to QM which did not yield rich quality characteristics.

\section{References}

Alañón, M.E., Castro-Vázquez, L., DíazMaroto, M.C., Hermosín-Gutiérrez I., Gordon M.H. and Pérez-Coello, M. S.,
(2011). Antioxidant capacity and phenolic composition of different woods used in cooperage. Food Chemistry, 129(4),15841590.

DOI:10.1016/j.foodchem.2011.06.013

Alonso, Á. M., Castro, R., Rodríguez, M. C., Guillén D. A., \&Barroso C. G. (2004). Study of the antioxidant power of brandies and vinegars derived from sherry wines and correlation with their content in polyphenols. Food Reserch International, 37(7), 715-721.

DOI:10.1016/j.foodres.2004.03.007

Bautista-Ortín, A. B., Lencina, A. G., CanoLópez, M., Pardo-Mínguez, F., López-Roca, J. M. and Gómez-Plaza, E. (2008). The use of oak chips during the ageing of a red wine in stainless steel tanks or used barrels: Effect of the contact time and size of the oak chips on aroma compounds. Australian Journal of Grape and Wine Research;14(2),63-70. DOI:10.1111/j.1755-0238.2008.00008.x

Cerezo, A. B., Tesfaye, W., Torija, M. J., Mateo, E., García-Parrilla, M. C. and Troncoso, A. M. (2008). The phenolic composition of red wine vinegar produced in barrels made from different woods.

Food 
Chemistry;109(3),606-615.

DOI:10.1016/j.foodchem.2008.01.013

Cerezo, A.B., Álvarez-Fernández, M.A., Hornedo-Ortega, R., Troncoso, A. M. and García-Parrilla, M. C. (2014). Phenolic composition of vinegars over an accelerated aging process using different wood species (acacia, cherry, chestnut, and oak): Effect of wood toasting. Journal of Agricultural and Food Chemistryistry,62(19),4369-4376. DOI:10.1021/jf500654d

Cerezo, A.B., Tesfaye, W., Soria-Díaz, M. E., Torija, M. J., Mateo E., Garcia-Parrilla, M. C., \&Troncoso, A. M.(2010). Effect of wood on the phenolic profile and sensory properties of wine vinegars during ageing. Journal of Food Composition and Analysis, 23(2), 175-184.

DOI:10.1016/j.jfca.2009.08.008

Cerezo, A.B., Tesfaye, W., Soria-Díaz, M. E., Torija M.J., Mateo E., Garcia-Parrilla M. C., and Troncoso, A. M.(2010). Effect of wood on the phenolic profile and sensory properties of wine vinegars during ageing. Journal of Food Composition and Analysis, 23(2), 175-184.

DOI:10.1016/j.jfca.2009.08.008

Chavenetidou, M., Kakavas, K. and Birbilis, D. (2019). Shrinkage and swelling of Greek chestnut wood (Castanea sativa Mill.) in relation to extractives presence. 3rd International Conference on Composite Material, Polymer Science and Engineering, Bangkok, Thailand, 2019, http://www.cmpse.org/.

De Rosso, M., Cancian, D., Panighel, A., Dalla Vedova A. and Flamini R.(2009), Chemical compounds released from five different woods used to make barrels for aging wines and spirits: Volatile compounds and polyphenols. Wood Science and Technology,43(5-6),375-385.

DOI:10.1007/s00226-008-0211-8

Del Alamo Sanza, M., Nevares Domínguez, I., Cárcel Cárcel, L. M., \&Navas Gracia, L.(2004), Analysis for low molecular weight phenolic compounds in a red wine aged in oak chips. Analytica Chimica Acta, 513(1),229-237.

DOI:10.1016/j.aca.2003.11.041

Figueiredo-González, M., Cancho-Grande, B., Simal-Gándara, J., Teixeira, N., Mateus, N., and De Freitas, V.(2014). The phenolic chemistry and spectrochemistry of red sweet wine-making and oak-aging. Food Chemistry.152,522-530.

DOI:10.1016/j.foodchem.2013.12.018

García Parrilla, M.C., Heredia, F.J., Troncoso, A.M. (1999). Sherry wine vinegars: phenolic composition changes during aging. Food Research International, 32:433440.https://doi.org/10.1016/S0963969(99)00105-2.

Hitos, P., Pons, A., Martin, de la Hinojosa, I, Gomez, R., Hernandez, A. and Muñoz, J., (2000). Validation of analysis methods for total, fixed and volatile acidity of nonvolatile reducing substances, copper and zinc in wine vinegars. No. 115, Green Sheet of OIV.

Kakavas, K. Chavenetidou, M. and Birbilis, D. (2018). Chemical Properties of Greek Stump Chestnut (Castaneas ativa Mill.).Natural Products Chemistry \& Research, 6,4. DOI: 10.4172/2329-6836.1000331.

Kanakaki, E., Siderakou, D., Kallithraka, S., Makris D. (2015). Effect of the degree of toasting on the extraction pattern and profile of antioxidant polyphenols leached from oak chips in model wine systems. European Food Research and Technology, 240(5).

DOI: 10.1007/s00217-014-2410-X

Karvela, E., Makris, D. P., Kefalas, P., \& Moutounet, M. (2008). Extraction of phenolics in liquid model matrices containing oak chips: Kinetics, liquid chromatography-mass spectroscopy characterisation and association with in vitro antiradical activity. Food Chemistry, 110(1), 263-272.

DOI:10.1016/j.foodchem.2008.02.001

Kawa-Rygielska, J., Adamenko, K., Kucharska, A.Z., PióreckiN.(2018). Bioactive Compounds in Cornelian Cherry Vinegars, Molecules, MDPI, 23,379. 
DOI: 10.3390/molecules23020379.

Martínez-Gil, A., Cadahía E., Fernández de Simón, B., Gutiérrez-Gamboa, G., Nevares, I., and del Álamo-Sanza, M.(2019). Phenolic and volatile compounds in quercushumboldtiibonpl. wood: Effect of toasting with respect to oaks traditionally used in cooperage. Science of Food and Agriculture,99(1),315-324.

DOI:10.1002/jsfa.9190

Mudura, E. et al.(2018). Brown beer vinegar: A potentially functional product based on its phenolic profile and antioxidant activity. Journal of the Serbian Chemical Society, 83 (1):19-30.DOI:10.2298/JSC170803107M.

Psarra, C., Gortzi, O. and Makris, D. P. (2015), Kinetics of polyphenol extraction from wood chips in wine model solutions: Effect of chip amount and botanical species. Journal of International Brewing, 121(2),207-212. DOI:10.1002/jib.212

Sanz, M., de Simon, B. F., Munoz, E.E., Cadahía, A.M., Hernandez, E.T., Estrella, I. and Pinto E. (2011). Effect of Toasting Intensity at Cooperage on Phenolic Compounds in Acacia (Robiniapseudoacacia) Heartwood. Journal of Agricultural and Food Chemistry, 59, 3135-3145dx. doi.org/10.1021/jf1042932

Sanz, M., Cadahía, E., Esteruelas, E., Muñoz, A. M., Fernández De Simón, B., Hernández, T. and Estrella, I. (2010). Phenolic compounds in cherry (prunusavium) heartwood with a view to their use in cooperage, Journal of Agricultural and Food Chemistry, 58(8),4907-4914. DOI:10.1021/jf100236v

Sanz, M., De Simón, B. F., Cadahía, E., Esteruelas E., Muñoz Á. M., Hernández M. T., \& Estrella, I. (2012). Polyphenolic profile as a useful tool to identify the wood used in wine aging, Analytica Chimica Acta;732,33-45.

DOI:10.1016/j.aca.2011.12.012

Sanz, M., Fernández de Simón, B., Esteruelas E., Muñoz, Á. M., Cadahía, E., Hernández, M. T., Martinez J.(2012). Polyphenols in red wine aged in acacia (robiniapseudoacacia) and oak (quercuspetraea) wood barrels. Analytica Chimica Acta, 732, 83-90. DOI:10.1016/j.aca.2012.01.061

Sanz, M., Cadahía, E., Esteruelas, E., Muñoz, Á. M., Fernández De Simón, B., Hernández, T., \&Estrella, I. (2010). Phenolic compounds in chestnut (Castanea sativa Mill.) heartwood.effect of toasting at cooperage. Journal of Agricultural and Food Chemistry. 58(17), 9631-9640.

DOI:10.1021/jf102718t

Sarni, F., Moutounet, M., Puech, J. and Rabier P. (1990). Effect of heat treatment of oak wood extractable compounds. Holzforschung,44(6),461-466.

DOI:10.1515/hfsg.1990.44.6.461

Schwarz, M., Rodríguez, M., Martínez, C., Bosquet, V., Guillén, D. and Barroso, C. G.(2009). Antioxidant activity of brandy de jerez and other aged distillates, and correlation with their polyphenolic content. Food Chemistry, 116(1),29-33. DOI:10.1016/j.foodchem.2009.01.096

Tesfaye, W., Morales, M. L., Benítez, B., García-Parrilla, M. C., \& Troncoso, A. M.(2004). Evolution of wine vinegar composition during accelerated aging with oak chips. Analytica Chimica Acta,513(1),239-245.

DOI:10.1016/j.aca.2003.11.079

Zhang, B., Cai, J., Duan, C., Reeves ,M. J., \& He, F. (2015). A review of polyphenolics in oak woods. International Journal of Molecular Sciences,16(4),6978-7014. DOI:10.3390/ijms16046978

\section{Acknowledgment}

We warmly thank Mr. Paleogiannis D.Mscand Mr. Plotas N. for the technical support. 